\title{
Managing Wildfire Events: Risk-Based Decision Making Among a Group of Federal Fire Managers
}

\author{
Robyn S. Wilson, ${ }^{1 *}$ Patricia L. Winter, ${ }^{2}$ Lynn A. Maguire, ${ }^{3}$ and Timothy Ascher ${ }^{1}$
}

\begin{abstract}
Managing wildfire events to achieve multiple management objectives involves a high degree of decision complexity and uncertainty, increasing the likelihood that decisions will be informed by experience-based heuristics triggered by available cues at the time of the decision. The research reported here tests the prevalence of three risk-based biases among 206 individuals in the USDA Forest Service with authority to choose how to manage a wildfire event (i.e., line officers and incident command personnel). The results indicate that the subjects exhibited loss aversion, choosing the safe option more often when the consequences of the choice were framed as potential gains, but this tendency was less pronounced among those with risk seeking attitudes. The subjects also exhibited discounting, choosing to minimize short-term over long-term risk due to a belief that future risk could be controlled, but this tendency was less pronounced among those with more experience. Finally, the subjects, in particular those with more experience, demonstrated a status quo bias, choosing suppression more often when their reported status quo was suppression. The results of this study point to a need to carefully construct the decision process to ensure that the uncertainty and conflicting objectives inherent in wildfire management do not result in the overuse of common heuristics. Individual attitudes toward risk or an agency culture of risk aversion may counterbalance such heuristics, whereas increased experience may lead to overconfident intuitive judgments and a failure to incorporate new and relevant information into the decision.
\end{abstract}

KEY WORDS: Discounting; experience; loss aversion; risk attitude; wildfire

\section{INTRODUCTION}

Throughout the late 19th century and most of the 20th century, risks associated with wildfire were addressed by suppressing fires as quickly as possible. However, research in the 1960s began to suggest that fire exclusion has adverse effects on the forest as well as contributes to larger and more damaging wildfires in the future. ${ }^{(1)}$ This led many federal management

${ }^{1}$ School of Environment and Natural Resources, The Ohio State University.

${ }^{2}$ Pacific Southwest Research Station, USDA Forest Service.

${ }^{3}$ Nicholas School of the Environment, Duke University.

*Address correspondence to Robyn S. Wilson, 2021 Coffey Road, 210 Kottman Hall, Columbus, OH 43210, USA; wilson.1376@osu.edu. agencies to explore tactics other than suppression to mitigate growing wildfire risks. Both the National Park Service and the Forest Service introduced prescribed burning into their fire policy in the 1970s as a means to managing high fuel loads; however, severe wildfires continued throughout the 1990s. ${ }^{(1,2)}$ A mid1990s review of federal fire policy recognized fire as a critical natural process and directed federal agencies to integrate fire into resource management plans on a landscape scale to reduce fuels and resulting risks from catastrophic wildfire. ${ }^{(3)}$ In addition to prescribed burning, another way to integrate fire across the landscape is through wildland fire use (WFU), a practice that allows a wildfire to burn to achieve ecological and fuel management objectives. ${ }^{(2)}$ According to federal fire policy, WFU is to be given equal 
consideration along with suppression. To encourage this consideration, fire management plans are developed to prepare line officers (i.e., district rangers and forest supervisors) to quickly evaluate the risks and benefits associated with wildfire across temporal and spatial scales to make an informed choice, with authority then delegated to incident command personnel. ${ }^{(4)}$ Ideally, the line officer should be able to consider current conditions and choose between wildfire suppression for the protection of human life and property, or WFU to achieve resource management objectives as dictated by the plan. ${ }^{(3)}$ However, many have argued that despite a recognized need to maintain fire on the landscape, line officers are reluctant to accept the risks associated with fire (prescribed or wild), and that restrictive policies and a lack of qualified fire use personnel create pressure to suppress. ${ }^{(5,6)}$ Furthermore, annual funds spent on suppression continue to increase, providing some evidence for implementation failing to reflect the intent of the policy. ${ }^{(7)}$

Managing wildfire events to achieve multiple management objectives and balance short- versus long-term risks across spatial scales involves a high degree of decision complexity and uncertainty, increasing the likelihood that fire management decisions will be malleable ${ }^{(8)}$ and informed by mental short-cuts or experience-based heuristics that are triggered by available cues at the time of the decision. ${ }^{(9)}$ Research has documented a number of factors that influence the choice between suppression and WFU (e.g., safety and accountability concerns, public perceptions, resource availability, perceived risk). ${ }^{(10-13)}$ What is less certain is whether or not management decisions are driven by a deliberative analysis of these factors and the risks posed by each, or a more intuitive, heuristic-based approach to decision making. Maguire and Albright ${ }^{(14)}$ suggest that individual fire management decisions are often the result of the overuse of risk-based heuristics, leading to general risk aversion in the short term and a failure to meet stated management objectives. For example, the perceived risk associated with certain management techniques (e.g., WFU) may prevent such techniques from being adequately considered during the decision-making process compared to other tactics perceived as less risky (e.g., suppression). ${ }^{(11)}$ In fact, between 2002 and 2004 , only $25 \%$ of the lightning-caused fires on USDA Forest Service designated wilderness occurred in areas approved for WFU, and only $40 \%$ of those events were actually managed using WFU. ${ }^{(15)}$ Recent studies provide ad- ditional evidence that decisions to suppress rather than engage in WFU even when the fire management plan allows it may be influenced by personal discomfort with uncertainty and a tendency to err on the side of caution in predicting risk, ${ }^{(16,17)}$ perhaps leading managers to favor tactics (e.g., suppression) that they perceive as less likely to result in negative outcomes. ${ }^{(18,19)}$

The specific heuristics and biases that may be most relevant to managing wildfire events include excessive aversion to losses; ${ }^{(20)}$ inordinate attention to short-term risk, essentially discounting future or long-term risk; ${ }^{(21)}$ and a desire to maintain the status quo. ${ }^{(22)}$ The majority of the evidence for these biases comes from laboratory experiments conducted with the general population for relatively simple decisions. ${ }^{(9,23)}$ Although there is evidence of these same biases being exhibited by individuals in domains where they have a depth and breadth of experience (for an example, see extensive research on medical decision making ${ }^{(24,25)}$, there is less evidence of how these individuals with a high degree of expertise make decisions in contexts involving consequences at multiple levels (individual to societal to institutional) and strongly held expectations or preferences across these same levels. ${ }^{(26)}$

The goal of the study reported here was to test the prevalence of these biases in the context of wildfire risk management among a population of "experts" or individuals with both a depth and breadth of experience in this decision context. We also wanted to explore other factors that may enhance understanding of risk-based decision making among these individuals, in particular their individual risk attitudes, risk perceptions, and years of experience in fire management. Our questions of interest include: Are fire management personnel subject to the heuristics and biases often attributed as the cause of their decision behavior? Are these errors in judgment more pronounced among individuals with greater experience? Are individual differences in risk perceptions and attitudes more powerful at explaining choice behavior than common biases in judgment?

\section{METHODS}

\subsection{Subjects}

Study participants were USDA Forest Service personnel from two lines of authority including Incident Command (Incident Commander, Deputy Incident Commander, and Operations Chief) and Line 
Officer (Forest Supervisor and District Ranger). These participants were selected because line officers ultimately make the final go-no go decision in line with fire management and response plans, and then delegate the execution of that decision to incident command. ${ }^{(6)}$ Both roles function cooperatively through the life of a fire event so both perspectives are essential in understanding Forest Service fire management decisions.

All 645 individuals with these position titles in the USDA Forest Service were recruited via email to complete the online instrument developed in Zoomerang. ${ }^{4}$ A total of 613 were successfully contacted, and 260 subjects agreed to participate for an initial response rate of $42 \%$. After removing incomplete responses, the final sample for data analysis was 206 (34 incident command personnel and 172 line officers) for a final adjusted response rate of $34 \%$ (37\% for incident personnel and $30 \%$ for line officers). An additional 107 subjects were randomly selected from the nonresponders and telephoned to participate in an abbreviated survey (see Appendix). The nonresponders exhibited no differences in terms of experience, position, or region. However, they did tend to report more cautious risk attitudes, lean more toward suppression for their status quo, and believe that fire use consequences were less known. These results indicate that our current sample may have been biased toward those individuals interested in and willing to support WFU. This is not particularly concerning as we found evidence of risk-based biases even among these perhaps less cautious individuals.

\subsection{Experimental Design}

Subjects participating in the study were randomly assigned to one of four instruments containing three separate decision scenarios designed to assess (1) an aversion to loss, (2) the tendency to discount long-term risk, and (3) a desire to maintain the status quo (see detailed sections later). In each scenario, subjects were given information about a hypothetical wildfire event and asked to make a choice that best reflected how they would respond if presented with that scenario on the job. ${ }^{5}$ Open-ended

\footnotetext{
${ }^{4}$ The use of trade or firm names in this article is for reader information only and does not imply endorsement by the U.S. Department of Agriculture of any product or service.

${ }^{5}$ Wiseman and Levin ${ }^{(26)}$ report that there is no difference in subject choice between scenarios involving real versus hypothetical consequences. The use of scenarios is an accepted practice in the study of risk-related decision making (see, e.g., Ref. 27). Furthermore, scenarios are now being used to train and guide decision-
}

comments were solicited following each scenario so that subjects could further explain the reasoning behind their choice.

\subsubsection{Scenario 1-Loss Aversion}

The first scenario employed a $2 \times 2$ betweensubjects design in which each subject was told to imagine that a wildfire had broken out placing 100 residences at risk. Half of the subjects were told that their own home and community were at risk whereas the other half were told that their own home and community were not at risk (i.e., impersonal/personal risk manipulation). Subjects were then given two options that they were told were consistent with their wildfire management plan, and asked to choose between the two options. Option 1 was the certain option (i.e., sure to save 25 homes or lose 75 homes), whereas Option 2 represented a gamble with the same expected value as the certain option (i.e., $25 \% / 75 \%$ chance of saving/losing 100 homes and a $75 \% / 25 \%$ chance of saving/losing no homes). Half of the subjects were presented with the options framed as homes saved whereas the other half were presented with homes lost (i.e., gain/loss frame manipulation). Subjects were then asked to explain the reason for their choice (see Appendix).

\subsubsection{Scenario 2-Discounting}

The second scenario employed a one-way between-subjects design in which subjects were told that a wildfire had broken out and they had nine management options available, each requiring a tradeoff between short-term and long-term risk, more specifically: the probability of a catastrophic fire occurring within the next year or within the next 10 years. Subjects were then presented with one of four management objectives to consider (i.e., protecting ecosystem health, property, endangered species, or public safety), along with a figure demonstrating the shortversus long-term tradeoff required by each option (where Option 1 resulted in a 0.1 probability of catastrophic fire in the short term and a 0.9 probability of catastrophic fire in the long term, Option 2 a 0.2 probability in the short term and a 0.8 probability in the long term, and so on ending at Option 9 with a 0.9 probability of catastrophic fire in the short term and a 0.1 probability of catastrophic fire in the long term). They were then asked to choose the option that was

making in complex environments and to evaluate the quality of decisions (see, e.g., Ref. 28). 
most appropriate, keeping in mind their specific objective of interest, and explain the reason for their choice (see Appendix).

\subsubsection{Scenario 3-Status Quo}

The third scenario employed a between-subjects design in which all of the subjects were first asked to imagine that a fire breaks out in a Wilderness area, and they have the flexibility to choose between suppression and initiating WFU activities. They were told that public safety and private property are not at risk. Subjects were then asked to indicate how they have responded to such a scenario in the past by engaging in suppression or fire use (designed to measure their status quo for that decision). They were then given an opportunity to list the factors that drove their decisions in the past. Next, subjects were presented with one of two decision trees either presenting both fire use and suppression as risky choices, each with two possible outcomes, or presenting fire use as a risky choice but suppression as a certain choice with only one potential outcome. They were reminded that public health and safety were not at risk, but that the wildfire would have differing impacts on ecosystem health, agency resources, and agency reputation, as represented in the decision tree. Subjects were then asked to indicate which decision they would recommend given the information provided in the tree, and to explain the reason for their choice (see Appendix).

\subsection{Measures of Risk Attitudes, Perceived Risk, and General Decision Factors}

As potential covariates in the experimental analyses, subjects were asked a series of questions aimed at measuring their individual risk attitudes, risk perceptions associated with suppression and fire use, the importance of various factors in their "go-no go" decision regarding whether to allow a wildfire to burn or engage in suppression activities, and their number of years in fire management. Because no contextspecific measure of risk attitude was available, we developed five statements aimed at measuring risk attitude in the context of wildfire management. Subjects rated five items on a scale from 1 to 7 (where $1=$ extremely unlikely, 7 = extremely likely, and the midpoint of $4=$ unsure). These five statements were: (1) take action that is perceived by many as risky; (2) avoid action that is perceived by many as risky; (3) use all resources at my disposal to minimize poten- tial negative outcomes; (4) behave cautiously when managing wildland fires; and (5) accept risk of fire escaping to protect ecosystem health.

The risk perception measures for suppression and WFU were developed based on psychometric paradigm research identifying the main factors characterizing perceived risk. ${ }^{(29,30)}$ Specifically, subjects were asked to separately rate to what extent fire suppression and WFU are ecologically harmful or beneficial (from $1=$ extremely ecologically harmful to $7=$ extremely ecologically beneficial), to what extent the consequences of each are unknown or known (from $1=$ consequences largely unknown to $7=$ consequences largely known), to what extent they are unpredictable or predictable (from $1=$ completely unpredictable to $7=$ completely predictable), and to what extent each is risky or safe (from $1=$ extremely risky to $7=$ completely safe).

Factors in the "go-no go" decision were rated on a scale from 1 to 7 (where 1 = extremely unimportant, $7=$ extremely important, and $4=$ neither unimportant nor important). These factors, based on those identified in past research, ${ }^{(11)}$ include Forest Service mandates, efficient and effective use of USDA FS personnel and equipment, minimizing short-term risk, lack of scientific knowledge or uncertainty within the agency, public perceptions of agency decisions, lack of financial resources, management constraints in the wildland-urban interface, timber or forest product standards, air quality standards, weather conditions, existence of culturally or archaeologically protected features, existence of threatened or endangered species, potential litigation, potential for fire escape or burn outside of the prescribed area, past personal experience with fire, minimizing long-term risk, lack of integration across managing agencies, and constraints of the existing fire management plan.

\subsection{Hypotheses}

For scenario 1, exploring loss aversion, we expected that the sure thing (as opposed to the gamble) would be preferred by (i) individuals presented with the consequences in terms of gains, (ii) individuals not experiencing risk to their own homes, (iii) risk-averse individuals, and (iv) individuals with fewer years of experience. For scenario 2 , exploring discounting of long-term risk, we expected that minimizing short-term risk (as opposed to minimizing long-term risk) would be preferred (i) across each management objective, (ii) by risk-averse 
individuals, (iii) by individuals who rate minimizing short-term risk as important, and (iv) by individuals with fewer years of experience. For scenario 3, exploring status quo bias and aversion to loss, we expected that suppression (as opposed to fire use) would be preferred by (i) individuals identifying suppression as their status quo, (ii) individuals in the risk-certain frame (as opposed to the riskrisk frame), (iii) individuals indicating high perceived risk associated with fire use, and (iv) individuals with greater years of experience.

\subsection{Analyses}

Binary logistic regression was used to test the hypotheses in scenarios 1 and 3, and multinomial logistic regression was used to test the hypotheses in scenario 2 (where the nine potential management options were combined into a preference for minimizing short-term risk, a preference for balancing short-term and long-term risk, and a preference for minimizing long-term risk). Paired $t$-tests were used to compare differences in perceived risk between fire use and suppression. The open-ended comments were coded according to concepts that emerged as explanatory reasons for the choices, and a secondary coder was used to assess reliability.

\section{RESULTS}

\subsection{Subjects}

Respondents were largely male (73\%) and operating at the forest (as opposed to district or national) level $(87 \%)$. Years in their current position ranged from 0 to 35 (with a mean of 7), whereas years in fire management ranged from 0 to 46 (with a mean of 22). A majority $(71 \%)$ reported experiencing fire on the job within the past 9 months, and the majority ( $88 \%)$ was moderately or extremely confident in their ability to make informed fire management decisions.

Participation was broadly represented across the USDA FS regions with between $10 \%$ and $18 \%$ of the respondents coming from each region, with the exception of the Eastern region $(6 \%)$ and the Alaskan region (1\%). Approximately $17 \%$ of the respondents were in incident command (IC) positions, and $84 \%$ of the respondents were line officers (of which $70 \%$ were district rangers), which generally reflects the composition of the original sample. IC personnel had significantly more years of experience in fire management ( 26 as opposed to 21 years, $t=2.888, p=0.004$ ), more recent experience with fire (last 3-6 months as opposed to 6-9 months, $t=5.092, p=0.000$ ), and were significantly more confident in their fire management decisions (extremely as opposed to moderately confident, $t=6.655, p=0.000$ ).

\subsection{Reliability and Coding Analyses}

Cronbach's $\alpha$ was used to measure reliability and identify items representing the best measure of risk attitude and perceived risk. Two of the original five risk attitude items (i.e., taking action that is perceived by many as risky, avoiding action that is perceived by many as risky) were chosen for the final risk attitude measure (Cronbach's $\alpha=0.76$ ). None of the original fire use or suppression risk perception items were identified as reliable measures in combination (Cronbach's $\alpha<0.70$ ). As a result, the single item rating of suppression and fire use on a scale from extremely risky to completely safe was chosen for the final risk perception measure.

The open-ended comments for each of the three scenarios were coded for explanations of individual decisions. A second coder recoded a randomly selected $20 \%$ of the subject responses. Using Cohen's $\kappa$ as a measure of intercoder reliability, the two coders achieved the recommended minimum level of reliability (Cohen's $\kappa=0.86$ ).

\subsection{Descriptive Analyses}

The risk attitude measure revealed that, on average, fire managers were risk neutral $(\bar{X}=4.08$, $S E=0.10$ ), with approximately $52 \%$ of managers reporting general risk aversion and $48 \%$ reporting general risk seeking preferences. The tendency toward risk aversion was stronger for the items more closely linked to fire management (but not included in the risk attitude measure), where the majority of managers reported they were likely to use all resources at their disposal to minimize risk $(79 \%)$ and behave cautiously when managing wildfires (79\%). However, the majority also reported they were likely to accept the risk of fire escaping to protect ecosystem health $(68 \%)$. Analyses of open-ended comments about the choice between suppression and WFU indicate that many managers believe fire is necessary from an ecological perspective and that suppression activities can always be initiated to control a fire that escapes from prescription, perhaps explaining this comfort with the risk of fire escaping.

The risk perception measures revealed that, on average, fire managers believed fire use and 
suppression were neither risky nor safe $\left(\bar{X}_{\text {suppression }}=\right.$ $3.89, S E=0.12$ and $\bar{X}_{\text {fire use }}=4.05, S E=0.12$, paired $t$-test $=-1.310, p=0.19)$. Although only $5 \%$ actually chose the neutral option for both management options, approximately $50 \%$ of managers believed each was risky and $45 \%$ believed each was safe. For the other risk perception items, managers believed that the consequences of both suppression and fire use were well known $\left(\bar{X}_{\text {suppression }}=5.53, S E=0.09\right.$ and $\bar{X}_{\text {fire use }}=5.52, S E=0.08$, paired $t$-test $=0.05, p=$ 0.96). However, managers also believed that fire use and suppression differed with regard to ecological benefits and predictability. Specifically, fire use was perceived as more ecologically beneficial than suppression $\left(\bar{X}_{\text {suppression }}=3.68, S E=0.11\right.$ and $\bar{X}_{\text {fire use }}=$ 6.12, $S E=0.06$, paired $t$-test $=-20.05, p=0.00)$, and suppression was perceived as more predictable than fire use $\left(\bar{X}_{\text {suppression }}=5.28, S E=0.07\right.$ and $\bar{X}_{\text {fire use }}=$ 4.77, $S E=0.10$, paired $t$-test $=4.98, p=0.00)$.

The mean ratings for each general decision factor indicated that each was perceived as important (greater than 4 on a bi-polar 7-point scale). In rank order, the top five decision factors were weather $(\bar{X}=6.78, S E=0.05)$, interface constraints $(\bar{X}=$ $6.66, S E=0.06)$, efficient and effective use of resources $(\bar{X}=6.26, S E=0.06)$, potential for fire to escape $(\bar{X}=6.16, S E=0.07)$, and past personal experience $(\bar{X}=6.14, S E=0.07)$.

\subsection{Experimental Analyses}

\subsubsection{Scenario 1-Loss Aversion}

Initial analyses revealed that none of the chosen predictors were correlated. Binary logistic regression analysis was then used to measure the effect of the manipulated categorical predictors (i.e., gain/loss frame and personal/impersonal risk) and continuous covariate predictors (i.e., risk attitude and years of experience) on the dependent variable of choice between the sure thing and the gamble. The model with chosen predictors was significant $\left(\chi^{2}=87.31\right.$, df $=$ $5, p=0.00)$, explaining $36-48 \%$ of the variance in subject choice (Cox \& Snell $R^{2}=0.36$ and Nagelkerke $\left.R^{2}=0.48\right)$. The outcome frame manipulation $(B=2.91, S E=0.56$, Wald $=27.34, \mathrm{df}=1, p=0.00$, $\operatorname{Exp}(B)=18.43)$ and individual differences in risk attitude $(B=-0.294, S E=0.14$, Wald $=4.53$, df $=$ $1, p=0.03, \operatorname{Exp}(B)=0.75)$ significantly contributed to the predictive ability of the model, supporting hypotheses $\mathrm{i}$ and iii. More specifically, the odds of a manager choosing the sure thing were approximately
Table I. Scenario 1 Binary Logistic Regression Results Demonstrating the Main Effect of the Two Manipulated Categorical Predictors, Interaction Effect of the Two Manipulated Variables, and Main Effect of the Two Continuous Covariates (Risk Attitudes and Years in Fire Management) on the Choice Between the Sure Thing and the Gamble

\begin{tabular}{lrrrrrr}
\hline & $B$ & $S E$ & Wald & df & Sig. & $\operatorname{Exp}(B)$ \\
\hline $\begin{array}{l}\text { Personal/impersonal } \\
\text { risk (cat) }\end{array}$ & 0.22 & 0.60 & 0.14 & 1 & 0.71 & 1.25 \\
$\begin{array}{l}\text { Gain/loss frame (cat) } \\
\text { Interaction (frame } \times\end{array}$ & 2.91 & 0.56 & 27.34 & 1 & 0.00 & 18.43 \\
$\quad$ risk) & 0.27 & 0.77 & 0.12 & 1 & 0.73 & 1.30 \\
$\begin{array}{l}\text { Risk attitude (cont) } \\
\text { Years in mgmt (cont) }\end{array}$ & -0.29 & 0.14 & 4.53 & 1 & 0.03 & 0.75 \\
$\quad$ Constant & 0.01 & 0.02 & 0.23 & 1 & 0.63 & 1.01 \\
& -0.83 & 0.77 & 1.16 & 1 & 0.28 & 0.44 \\
\hline
\end{tabular}

18 times higher for someone in the gain frame than in the loss frame. In addition, the more risk seeking a manager was, the less likely he or she was to choose the sure thing (odds of choosing the sure thing decreased by a factor of 0.75 for every one unit increase in risk seeking tendency). The personal/impersonal risk manipulation, interaction effect, and years of experience were not significant predictors of choice, failing to support hypotheses ii and iv (Table I, $p>0.05)$.

The open-ended explanations for the decision were coded into three categories: desire to avoid risk, willingness to accept risk, and other factors involved in the decision (largely firefighter and/or public safety). For those individuals choosing the sure thing, $76 \%$ attributed their choice to a desire to avoid risk, whereas $2 \%$ attributed their choice to being willing to accept risk (16\% cited other factors). For those individuals choosing the gamble, $78 \%$ attributed their choice to a willingness to accept risk, whereas $1 \%$ attributed their choice to wanting to avoid risk (19\% cited other factors). These results provide additional support for the framing manipulation having an effect on subject choices.

\subsubsection{Scenario 2-Discounting}

An initial correlation analysis of the independent factors and covariates identified a correlation between risk attitude and the importance of shortterm risk, as well as years of experience and the importance of long-term risk. Specifically, as risk seeking increases, the importance of short-term risk decreases $(r=-0.148, p<0.05)$, and as years of experience increases, the importance of long-term risk increases $(r=0.155, p<0.05)$. Given these results, 
the rated importance of short-term and long-term risk as general decision factors were not included as covariates in the regression analysis to include both risk attitudes and years of experience.

Multinomial logistic regression analysis was used to measure the effect of the manipulated independent factor (i.e., type of objective) and covariates (i.e., risk attitude and years in fire management) on the dependent variable of choice: minimizing short-term risk, balancing short- and longterm risk, or minimizing long-term risk. The model with chosen predictors was significant $\left(\chi^{2}=24.65\right.$, $\mathrm{df}=10, p=0.01$ ), explaining $12-14 \%$ of the variance in subject choice (Cox \& Snell $R^{2}=0.12$ and Nagelkerke $\left.R^{2}=0.14\right)$. For the choice between minimizing long- or short-term risk, years of experience $(B=0.05, S E=0.02$, Wald $=4.45, p=$ $0.04, \operatorname{Exp}(B)=1.05)$ and the management objective of ecosystem health $(B=2.15, S E=0.67$, Wald $=10.35$, df $=1, p=0.00, \operatorname{Exp}(B)=8.56$ ) were significant predictors, supporting hypothesis iv and partially supporting hypothesis i. More specifically, the odds of a manager choosing to minimize long-term over short-term risk increases by approximately 1 for every year of additional management experience, and by approximately 9 if the objective is protecting public health and safety rather than protecting ecosystem health. For the choice between balancing short-term and long-term risk or minimizing short-term risk, the management objective of ecosystem health $(B=1.19, S E=0.47$, Wald $=6.37, \mathrm{df}=1, p=0.01, \operatorname{Exp}(B)=3.29)$ is a significant predictor. Specifically, the odds of a manager choosing to balance short-term and long-term risk as opposed to minimizing short-term risk increases by approximately 3 if the objective is protecting public health and safety rather than protecting ecosystem health. Risk attitude was not a significant predictor, failing to support hypothesis ii (Table II, $p>0.05$ ).

The open-ended explanations for the decision were coded into four categories: a desire to balance short-term and long-term risk, a desire to address short-term risk, a desire to address long-term risk, and other factors (largely firefighter safety, achieving species management objectives, cost, and buying time to plan for and prevent future fires). Of the subjects who chose an option that guaranteed lower risk in the short term, $80 \%$ cited minimizing shortterm risk as the reason for their choice. More specifically, many cited the need to minimize short-term over long-term risk because one can plan for and prevent future fires (further demonstrating this tendency to discount long-term risk). Of subjects who chose the option that gave equal weight to short-term and long-term risk, $68 \%$ cited a need to balance risk as the reason for their choice. Of subjects who chose an option that guaranteed lower risk in the long term, $59 \%$ cited a need to minimize long-term risk as the main reason for their choice. These results indicate that a decision to minimize short-term risk may be largely driven by just that, a desire to minimize shortterm risk above all else. However, other factors may play increasing importance in the decision to minimize long-term risk. This choice may be less about simply wanting to minimize long-term risk, but also about other factors, such as achieving species management objectives.

\subsubsection{Scenario 3}

An initial correlation analysis of the covariates identified a correlation between risk attitude and the status quo, as well as perceived risk of suppression and WFU. Specifically, as risk seeking increases, the tendency to have chosen suppression in the past decreases $(r=-0.14, p<0.05)$, and as the perceived risk of suppression increases, so does the perceived risk of WFU $(r=0.46, p<0.01)$. Given these results, risk attitude and perceived risk of suppression were not included as covariates to include both the status $q u o$ choice and perceived risk of fire use.

Binary logistic regression analysis was used to predict the effect of the categorical (i.e., choice frame and status quo) and continuous variables (i.e., years of experience and perceived risk associated with WFU) on the choice between fire use and suppression. The model was significant $\left(\chi^{2}=31.52, \mathrm{df}=4\right.$, $p=0.00)$, explaining $15-42 \%$ of the variance in subject choice (Cox \& Snell $R^{2}=0.15$ and Nagelkerke $\left.R^{2}=0.42\right)$. Individual differences in the status quo $(B=3.56, S E=0.80$, Wald $=19.69, \mathrm{df}=1, p=$ $0.00, \operatorname{Exp}(B)=35.09)$ and years in fire management $(B=0.11, S E=0.05$, Wald $=5.10, \mathrm{df}=1, p=0.02$, $\operatorname{Exp}(B)=1.12)$ significantly contributed to the predictive ability of the model (Table III), supporting hypotheses i and iv. More specifically, the odds of a manager choosing suppression were approximately (i) 35 times higher for those who indicated suppression was their status quo as opposed to WFU, and (ii) one unit higher for every additional year of fire management experience. The choice frame manipulation $(p=0.91)$ and perceived risk of WFU $(p=0.12)$ were not significant predictors, failing to support hypotheses ii and iii. 
Table II. Scenario 2 Multinomial Logistic Regression Demonstrating the Effect of One Manipulated Independent Factor (Decision Objective) and Two Covariates (Years in Fire Management, Risk Attitude) on Subject Choice Among Minimizing Short-Term Risk, Balancing Short-Term and Long-Term Risk, and Minimizing Long-Term Risk

\begin{tabular}{|c|c|c|c|c|c|c|c|c|c|}
\hline \multirow[b]{2}{*}{ Dependent Variable } & \multirow[b]{2}{*}{ Predictors } & \multirow[b]{2}{*}{$B$} & \multirow[b]{2}{*}{$S E$} & \multirow[b]{2}{*}{ Wald } & \multirow[b]{2}{*}{ df } & \multirow[b]{2}{*}{ Sig. } & \multirow[b]{2}{*}{$\operatorname{Exp}(B)$} & \multicolumn{2}{|c|}{$\begin{array}{c}95 \% \mathrm{CI} \text { for } \\
\operatorname{Exp}(B)\end{array}$} \\
\hline & & & & & & & & Lower & Upper \\
\hline \multirow[t]{6}{*}{ Minimize long-term risk ${ }^{\mathrm{a}}$} & Intercept & -4.23 & 1.00 & 18.09 & 1 & 0.00 & & & \\
\hline & Years in fire mgmt & 0.05 & 0.02 & 4.45 & 1 & 0.04 & 1.05 & 1.00 & 1.09 \\
\hline & Risk attitude & 0.30 & 0.15 & 3.68 & 1 & 0.06 & 1.34 & 0.99 & 1.82 \\
\hline & Ecosystem health $^{\mathrm{b}}$ & 2.15 & 0.67 & 10.35 & 1 & 0.00 & 8.56 & 2.31 & 31.65 \\
\hline & Property ${ }^{b}$ & 1.05 & 0.69 & 2.33 & 1 & 0.13 & 2.87 & 0.74 & 11.07 \\
\hline & $\mathrm{T} \& \mathrm{E}$ species $^{\mathrm{b}}$ & 1.20 & 0.66 & 3.30 & 1 & 0.07 & 3.32 & 0.91 & 12.13 \\
\hline \multirow[t]{6}{*}{ Balance risk ${ }^{\mathrm{a}}$} & Intercept & -1.68 & 0.69 & 5.99 & 1 & 0.01 & & & \\
\hline & Years in fire mgmt & 0.02 & 0.02 & 1.19 & 1 & 0.28 & 1.02 & 0.99 & 1.05 \\
\hline & Risk attitude & 0.17 & 0.12 & 1.99 & 1 & 0.16 & 1.19 & 0.94 & 1.51 \\
\hline & Ecosystem health ${ }^{\mathrm{b}}$ & 1.19 & 0.47 & 6.37 & 1 & 0.01 & 3.29 & 1.31 & 8.28 \\
\hline & Property ${ }^{b}$ & 0.17 & 0.48 & 0.12 & 1 & 0.73 & 1.18 & 0.46 & 3.02 \\
\hline & $T \& E$ species $^{b}$ & 0.35 & 0.45 & 0.61 & 1 & 0.44 & 1.42 & 0.59 & 3.42 \\
\hline
\end{tabular}

${ }^{\mathrm{a}}$ The reference category is: Minimize short-term risk.

${ }^{\mathrm{b}}$ This reference category is: Protect public health and safety.

Table III. Scenario 3 Binary Logistic Regression Results Demonstrating the Effect of the Manipulated Categorical Predictor (Risk-Risk Versus Risk-Certain Choice Frame), One Categorical Covariate (Status Quo), and Two Continuous Covariates (Wildland Fire Use Risk Perception and Years in Fire Management) on the Choice Between Suppression and Fire Use

\begin{tabular}{lrrrrrr}
\hline & $B$ & $S E$ & Wald & df & Sig. & $\operatorname{Exp}(B)$ \\
\hline Status quo & 3.56 & 0.80 & 19.69 & 1 & 0.00 & 35.09 \\
$\begin{array}{l}\text { Choice frame } \\
\begin{array}{c}\text { WFU risk } \\
\text { perception }\end{array}\end{array}$ & -0.08 & 0.76 & 0.01 & 1 & 0.91 & 0.92 \\
$\begin{array}{c}\text { Years in fire } \\
\text { mgmt }\end{array}$ & 0.11 & 0.05 & 5.10 & 1 & 0.02 & 1.12 \\
$\begin{array}{l}\text { Constant } \\
\text { constant }\end{array}$ & -5.43 & 1.76 & 9.48 & 1 & 0.00 & 0.00 \\
\hline
\end{tabular}

The open-ended explanations for the decision in scenario 3 were coded into seven categories largely consistent with previous research:(11) logistical challenges (e.g., staffing, cost), benefits of fire on the landscape, agency issues (e.g., support, mandates), source of the ignition (e.g., human vs. lightning), safety, public involvement, and other factors. For both those choosing fire use and those choosing suppression, approximately half of the subjects cited logistical challenges and safety as the main reasons for their choice. For those choosing WFU, 39\% cited the benefits of fire as a reason (as opposed to only $18 \%$ of those choosing suppression). For those choosing suppression, $36 \%$ cited agency issues and limitation as a rea- son (as opposed to only $10 \%$ of those choosing fire use). These findings are consistent with past research showing that the decision to engage in WFU hinges on personal commitment to returning fire to the landscape, whereas inhibitors to fire use include resource availability, safety and agency support. ${ }^{(11)}$

\section{DISCUSSION}

The research reported here was designed to explore the factors influencing decision making among USDA Forest Service personnel with authority to choose to manage wildfire events through suppression or WFU. In particular, the scenarios were designed to test whether or not these individuals might be subject to common heuristics and biases in decision making that lead to an aversion to loss, a tendency to discount long-term risk, and a preference for maintaining the status quo. There was evidence that each of these biases may exist, although they were often more or less pronounced depending on individual differences in risk attitudes and years of experience. ${ }^{(31)}$

With regard to loss aversion, individuals who were presented information about the decision that primed them to focus on the potential gain associated with each option (i.e., homes saved) were more likely to take the safe option, avoiding the risky choice, despite the overall expected value of each option being the same (Fig. 1). This tendency toward loss 


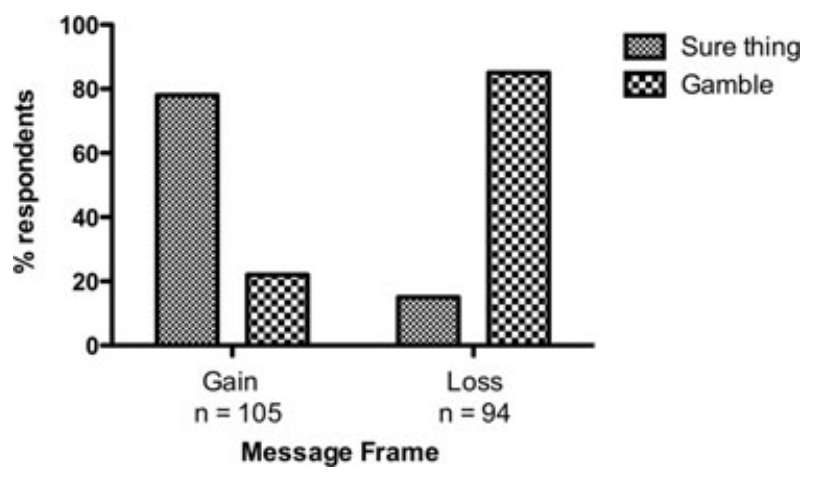

Fig. 1. Scenario 1 results showing the percentage of respondents who chose the sure thing versus gamble or risky option in the gain and loss frames. Subjects in the loss frame were more likely to choose the gamble whereas subjects in the gain frame were more likely to choose the sure thing.

aversion was less pronounced among managers who were more likely to seek risk in their everyday management decisions. These individuals were more likely to choose the gamble or the risky option regardless of how the decision relevant information was framed. These findings point to a potential cumulative effect in individual tendencies to seek or avoid risk when responding to wildfire events, leading to the potential for either overly cautious or overly risky behavior depending on the combination of the individual's risk attitude and the decision frame that is adopted based on available information. Given that fire managers must account for individual, societal, and organizational attitudes toward risk there is likely to be a disconnect between individual or personal risk preferences and those imposed by society or the agency. If the agency culture or mandate is to err on the side of caution (which many respondents felt was the case), there will be those who further enhance this position, whereas there will be those who counterbalance this position through their own personal preferences.

With regard to discounting, managers demonstrated a tendency to prefer minimizing short-term risk in their decision making, leading to general risk aversion in the short term and discounting of longterm risk (Fig. 2). One such explanation from a subject summed up the sentiments of many: "My immediate priority is to protect life and property now. Measures can be taken later to prevent the long term risk." Such sentiments indicate a perceived ability to control future catastrophic events, or a belief that the likelihood of such an event may shift, making it more important to address the immediate threat. However, this discounting was less pronounced among managers with more experience. One potential explanation is that with experience comes an increased ability to use intuitive expertise to inform decision making in a constructive way. Specifically, Kahneman and Klein ${ }^{(32)}$ suggest that skilled intuition results when the decision environment provides reliable cues and the individual has the opportunity to learn those cues. With time, it would be expected that fire managers would have an increased ability to recognize appropriate cues during the decision process, whereas individuals with less experience would not have the ability to recognize these cues.

Managers also appear to be subject to a status quo bias, choosing suppression in response to a wildfire event more often when their typical choice was suppression (Fig. 3). However, only 19 individuals or $10 \%$ identified suppression as their status quo response to a wildfire occurring in a wilderness area with an approved WFU plan. This response seems
Fig. 2. Scenario 2 results showing the percentage of respondents who chose an option that resulted in a greater reduction of short-term risk, a balance of reducing short- and long-term risk, or a greater reduction of long-term risk across the four decision objectives. With the exception of ecosystem health, respondents chose to minimize short-term risk more than long-term risk.

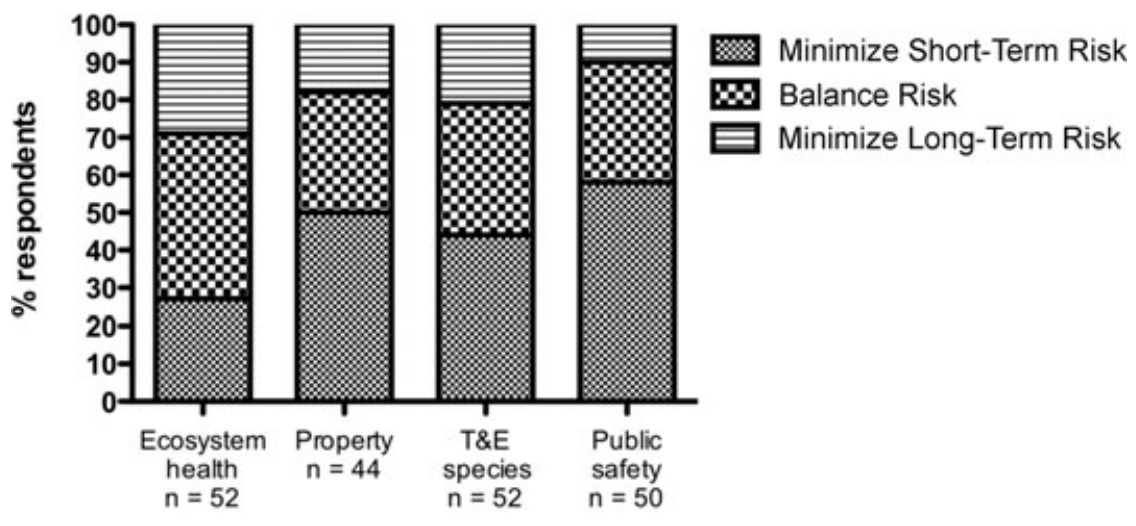

Objective 


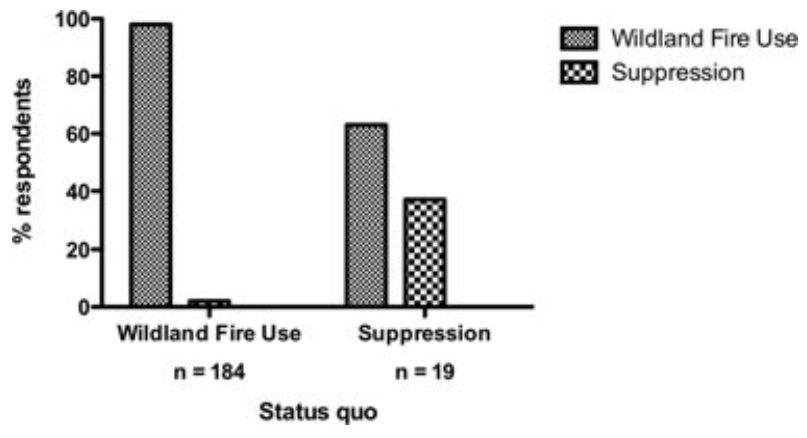

Fig. 3. Scenario 3 results showing the percentage of respondents who chose fire use and suppression within each of two groups created by their self-reported status quo.

contrary to current trends in agency decision making, where approximately $60 \%$ of lightning caused fires in approved WFU areas between 2002 and 2004 were suppressed. ${ }^{(15)}$ A potential explanation for this inconsistency between actual and reported decision making is twofold: (1) our sample may have been slightly biased toward those who were more comfortable with fire use as indicated by our nonresponse survey, and (2) many managers identified fire use as their status quo but then explained that choosing to engage in fire use does not preclude suppression. Fire use is not perceived as a permanent decision but rather an opportunity to achieve ecological benefits while maintaining the ability to suppress the fire if conditions or the probability of success changes. As a result, there is the potential for fire use to be chosen initially but abandoned for suppression given changing conditions.

Even so, the status quo bias was particularly pronounced among managers with more years of experience. This finding is consistent with a recent study of fire information users, which found that those with longer tenure in their position were less likely to rely on predictive information in making fire management decisions. ${ }^{(16)}$ These individuals were also less likely to take action based on that information when compared to individuals with shorter tenure in position, demonstrating an experience-based bias that leads to a greater reliance on fuzzy and intuitive processing in decision making. ${ }^{(33)}$ This finding is seemingly contradictory to the relationship between experience and discounting, where additional experience reduced use of that particular heuristic. One potential explanation is that, despite the tendency to recognize the importance of long-term risk management with increasing experience and not exhibit short-term risk aversion, this preference was only ex- hibited in the scenario where the specific management technique was not specified. When the choice was actually between fire use and suppression, individuals with more years in fire management may be more influenced by traditional agency practices, and more aware of the price paid by fire use gone wrong, increasing their reliance on a status-quo-biased intuitive judgment. As one such subject stated, "I would like to think I would select Fire Use if long-term forecasts and expected fire behavior/time remaining in fire season looked favorable. The agency and responsible officials will take a beating from our politicians and media if the fire goes poorly. And that is why fire use is so seldom selected. One aw-s**t, erases 10,000 atta-boys." The availability of an informed choice gone wrong is perhaps increased among those managers with greater experience.

The results of this study point to the need to carefully construct the decision process to assist managers in avoiding common heuristics and biases that result from (1) biased framing of decision relevant information, (2) an inability to address short- versus longterm risk tradeoffs, and (3) an overreliance on past experience, causing it to dominate rather than inform future decisions. Although intuition resulting from expertise can be very useful in some decision contexts, fire management is a context that does not fall neatly into the model of skilled intuition proposed by Kahneman and Klein. ${ }^{(32)}$ Our results provide support for the idea that with experience individuals have the ability to adequately learn the cues that lead to the adaptive use of heuristics and intuitive judgments. However, fire management is not a high-validity environment, or a static environment with predictable outcomes and reliable feedback. ${ }^{(34)}$ In addition, managers also have to make decisions that have important temporal and spatial consequences, adding to the complexity of the decision environment. As a result, fire managers cannot be expected to rely solely on intuition and learned expertise when responding to a wildfire event. Line officers are expected to guide their decisions based on the existing fire management plan, and from that decision delegate an approach to incident command. They are also required to continue to monitor and weigh the results of that decision and impacts on the ecosystem. In both cases expertise and experience inform these processes, but are never the sole source of information on which these choices are based.

In an attempt to help managers make more informed wildfire management decisions in this highly dynamic environment, the U.S. Forest Service uses 
a decision-support process that incorporates situational assessment, analysis of hazards and risk, selection of implementation actions, and documentation of decisions and rationale for those decisions. ${ }^{(35)}$ Tools are available to managers to support wildland fire decision making and steps in the decision process, for example, WFSA, or Wildland Fire Situation Analysis, and more recently the WFDSS (Wildland Fire Decision Support System; see Ref. 36). According to McDaniel, ${ }^{(36)}$ the WFDSS incorporates a stratified cost index that includes values at risk, the probability of fire spread, and values threatened, drawing from local public surveys and records. However, these tools may not take into account the need for information to be presented in a way that balances consideration of potential gains and losses, especially those that are short and long term. In addition, such tools may not be widely used given respondent comments that indicated a tendency to rely on experience, as well as individual, society, or agency tolerance for risk. One respondent commented, "I would not change my mind if I believed the conditions were good no matter what a graph/tree would show. Now my boss may change my mind, depending on the amount of risk they would be willing to take or not." Another stated, "[your] decision matrix [was] not that helpful, existing experience would indicate that it was the right decision." And finally: "The day line officers rely on decision trees is the day they should stop being a line officer." Cohen ${ }^{(18)}$ reported that the focus on suppression in the Wildland Urban Interface to minimize risk to residences is the major driver of exchanging short-term gains for longer term losses. This suggests an agency norm that perpetuates and aligns with the discounting principle, nested in a complex social and political environment. The future challenge will be for society and managing agencies to respect the role of intuitive expertise where it is appropriate, whereas individual managers must learn to recognize potential flaws in their intuition and the need to supplement decisions with additional training and support. Paired with that is the greater contextual challenge to address external pressures that continue to drive the focus on shorter term risk. ${ }^{(18)}$ Although recent guidance for federal wildland fire management suggests a consideration of longer term benefits, ${ }^{(35)}$ concerns over risks to life and property in the short term will remain considerable forces in fire management decision making.

The findings presented here shed light on the risk-based patterns of decision making by individuals with a breadth and depth of experience in a domain where the decision is both influenced by, and has an influence on, the individual decisionmaker, society, and the managing organization. As expected, these individuals often use the same heuristics and are subject to the same biases exhibited by laypeople; however, these intuitive short-cuts may be both enhanced or decreased by experience and individual attitudes toward risk. Existing support tools should be assessed for their ability to prevent excessive loss aversion, and in particular loss aversion in the short term. Such tools could present predicted impacts from suppression or WFU in terms of both gains and losses. In addition, they could include predictions of short-term versus long-term risks and benefits, and explicitly facilitate tradeoffs across this temporal dimension to avoid heuristic processing of this information.

In addition to improved support tools available at the time of the decision, the individual risk attitudes of managers could be assessed and tools and training personalized to prevent overly cautious or overly risky behavior. Tools could be evaluated for willingness and likelihood of reliance on information, along with an assessment of barriers to that reliance (see, e.g., Ref. 16). Finally, the findings presented here should be tested among other federal fire personnel (e.g., National Park Service, Bureau of Land Management), as each agency operates under the same federal fire policy, but different agency structures and cultures. The findings should also be tested for confirmation in naturalistic settings. For example, agencies could ensure the completion of decision logs and might add debriefing interviews following each wildfire event. Such consistent tracking mechanisms, which are in line with the current policy, could provide insight into the extent that these biases are reflected outside of hypothetical scenarios, and the degree to which personal experience predicts the outcome or the presence of a particular bias. They may also be helpful in understanding other factors implicit in decisions that affect selection of actions during a fire event. Pairing this with the work reported here will improve our understanding of how science can inform tools and application of tools to support and enhance fire management decisions.

\section{ACKNOWLEDGMENTS}

This study was funded by the USDA Forest Service, Pacific Southwest Research Station-Riverside. The authors thank Armando Gonzalez-Caban, $\mathrm{Ph} . \mathrm{D}$., for multiple reviews of the survey instrument and article, as well as Elke Schuster and David 
Olson for compiling the manager database and preparing the data for analysis. Finally, the authors thank the fire managers who took the time to participate in the survey.

\section{APPENDIX}

The following items were included in the followup nonresponse phone survey. The original, full survey instrument is available upon request at wilson.1376@osu.edu.

(1) Considering the majority of your wildfire experiences in the last 2 years, which designation best fits your USDA FS fire management role? Incident Commander, Deputy Incident Commander, Operations Chief, Forest Supervisor, District Ranger, None of the Above

(2) And, considering the location in which you conduct the majority of your fire management activities, would you say that it is at the national, regional, or forest level?

(3) How many years of experience do you have in fire management?

(4) To what extent does the USDA FS share your values about fire management? Does not share at all, Mostly does not share, Does not share a few, Neither, Shares a few, Shares most, Shares all

(5) Imagine that a fire breaks out in a Wilderness area, and you have to make a decision on how to respond. Your fire management plan allows you flexibility in choosing between suppression and WFU depending on the specific risks involved. In this case, the wildfire has occurred in an area that does not place public safety or private property at risk. When you have faced similar situations in the past, what was your typical response? Suppression or Fire Use

(6) How likely is it that you would behave cautiously when managing wildland fires? Extremely Unlikely, Moderately Unlikely, Somewhat Unlikely, Unsure, Somewhat Likely, Moderately Likely, Extremely Likely

(7) To what extent do you believe the consequences of fire suppression are unknown or known? Largely Unknown, Moderately Unknown, Somewhat Unknown, Neither Unknown nor Known, Somewhat Known, Moderately Known, or Largely Known

(8) And, using that same scale ... to what extent do you believe the consequences of fire use are unknown or known? Largely Unknown, Moderately Unknown, Somewhat Unknown, Neither Unknown nor Known, Somewhat Known, Moderately Known, or Largely Known

(9) Fire management decisions are obviously very complex and prone to influence from many different factors both within your control and outside your control. Assuming a wildfire has occurred, conditions specified in your fire use plan are met, and you were given the choice, how important are the following two factors in your "go-no go" decision regarding whether to allow the fire to burn to achieve resource objectives or engage in suppression activities? Extremely Unimportant, Moderately Unimportant, Somewhat Unimportant, Neither Unimportant nor Important, Somewhat Important, Moderately Important, or Extremely Important

i. Lack of scientific knowledge or uncertainty (within the agency)

ii. Interface constraints (e.g., presence of homes, public safety)

(10) Please indicate how confident you feel in your ability to make informed fire management decisions: Extremely Unconfident, Moderately Unconfident, Somewhat Unconfident, Neither Unconfident nor Confident, Somewhat Confident, Moderately Confident, or Extremely Confident

(11) And now, I'd like to ask the reason for your non-response to the survey invitations sent by Dr. Wilson and Dr. Winter (all possible reasons were noted): Lack of time, Lack of interest in surveys, Too many surveys, Problem with survey site, No official support or direction to participate, Other

\section{Scenario 1}

Imagine that a wildfire breaks out placing 100 residences at-risk. Your own home and community are (not) placed at-risk by the wildfire. You have two options that are both consistent with your fire management plan. However, both options carry some risk. (Subjects asked to pick one of the options below.)

Option 1: You are sure to save 25 (lose 75) homes

Option 2: You have a $25 \%(75 \%)$ chance of saving (losing) 100 homes and a $75 \%(25 \%)$ chance of saving (losing) no homes 


\section{Scenario 2}

Now imagine that a wildfire breaks out and you are considering your options for management. You have nine different options (each representing some combination of techniques) that are predicted to result in a certain amount of short-term and long-term risk to your objective of interest. In this case, you are primarily interested in minimizing risk to (subjects provided with one of the following):

(1) ecosystem health because of the remote location of the fire

(2) private property because of the proximity of the fire to a resort town where the residents have already been evacuated

(3) endangered species because of the immediate risk to a particular species of interest

(4) human health and safety because of the proximity of fire to an urban area

The risk posed by each management option reflects the probability that another wildfire event will occur over the specific time period and that the consequences of that fire will be catastrophic to your objective of interest. For example, management option 1 poses low short-term risk, or a $10 \%$ chance of fire within the next year with catastrophic consequences for $X$. However, management option 1 does pose high long-term risk, or a $90 \%$ chance of fire within the next 10 years with catastrophic consequences for $X$.

Please select the option that is most acceptable to you based on the trade off between short and longterm risk. Remember that you are primarily concerned in this context about minimizing risk to $X$.

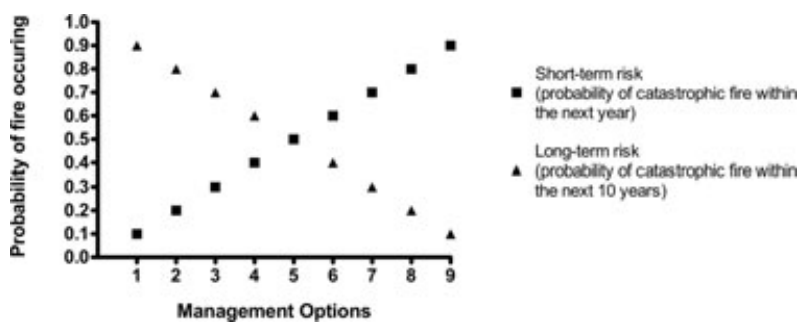

\section{Scenario 3}

For this scenario, imagine that a fire breaks out in a Wilderness area, and you have to make a decision on how to respond. Your fire management plan allows you flexibility in choosing between suppression and WFU depending on the specific risks involved.
In this case, the wildfire has occurred in an area that does not place public safety or private property at risk. When you have faced similar scenarios in the past, what was your typical response? (Subjects asked to choose suppression or fire use.)

Now consider in making the previous choice that you had the following decision tree to assist you. In the scenario described previously recall that this wildfire will have no impacts on public health or safety but it will have differing impacts on ecosystem health, agency resources, and agency reputation. Positive signs indicate a positive outcome given the particular decision (i.e., ecosystem health improved, resources used efficiently). Negative signs indicate a negative outcome (i.e., ecosystem health decreased, inefficient use of resources, decreased trust in agency), whereas a double negative indicates even greater negative consequences.

(Subjects provided with one of the two following figures and then asked choose fire use or suppression given the information in the decision tree.)
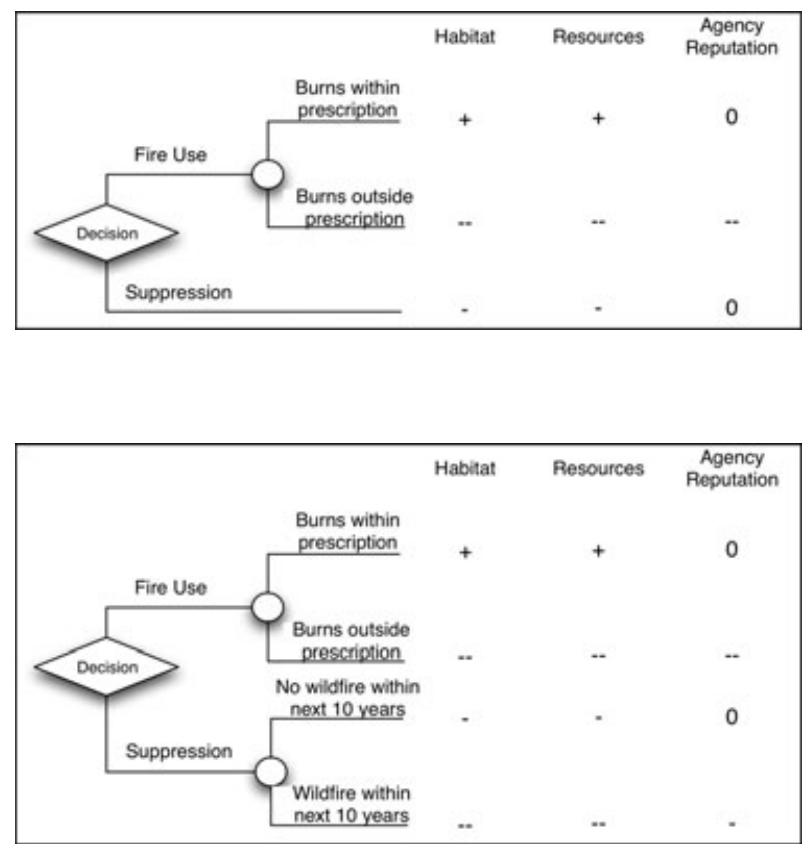

\section{REFERENCES}

1. Pyne SJ. Fire in America: A Cultural History of Wildland and Rural Fire. Princeton, NJ: Princeton University Press, 1982.

2. van Wagtendonk JW. The history and evolution of wildland fire use. Fire Ecology, 2007; 3(2):3-17. 
3. National Wildfire Coordination Group. Review and update of the 1995 federal wildland fire management policy, National Interagency Fire Center, 2001.

4. Miller C. Wildland fire use: A wilderness perspective on fuel management, USDA Forest Service Proceedings, Vol. RMRS-P-29, 2003.

5. Dellasala DA, Williams JE, Deacon Williams C and Franklin JF. Beyond smoke and mirrors: A synthesis of fire policy and science. Conserv Biol, 2004; 18(4):976-986.

6. USDA Office of Inspector General Western Region. Forest Service Large Fire Suppression Costs, Report \#08601-44-SF, 2006.

7. Donovan GH, Brown TC. Be careful what you wish for: The legacy of Smokey Bear. Frontiers in Ecology and the Environment, 2007; 5(2):73-79.

8. Slovic P. The construction of preference. American Psychologist, 1995; 50:364-371.

9. Tversky A, Kahneman D. Judgment under uncertainty: Heuristics and biases. Science, 1974; 185:1124-1131.

10. Cortner HJ, Taylor JG, Carpenter EH, Cleaves DA. Factors influencing forest service fire managers risk behavior. For Sci, 1990; 36(3):531-548.

11. Williamson MA. Factors in United States forest service district rangers decision to manage a fire for resource benefit. Int $J$ Wildland Fire, 2007; 16(6):755-762.

12. Wise CR, Freitag C. Balancing accountability and risk in program implementation: The case of national fire policy. Journal of Public Administration Research and Theory, 2002; 12(4):493-523.

13. Black A, Williamson M, Doane D. Wildland fire use barriers and facilitators. Fire Management Today, 2008; 68(1):10-14.

14. Maguire LA, Albright EA. Can behavioral decision theory explain risk-averse fire management decisions? For Ecol Manag, 2005; 211:47-58.

15. Wells G. Wildland fire use: Managing for a fire-smart landscape. In Rohling K, Kapus J, Swedberg T (eds). Fire Science Digest. Boise, ID: Joint Fire Science Program, 2009.

16. Winter PL, Bigler-Cole H. Information needs, acceptability of risk, trust and reliance: The case of National Predictive Services customers. In Lee DC, Beatty J, Shaw CG, Pye JM, Sands Y (eds). Forest Encyclopedia Network, 2008. Available at http://www.forestencyclopedia.net/p/p5/ p3389/p3687/view.

17. Doane D, O'Laughlin J, Morgan P, Miller C. Barriers to wildland fire use: A preliminary problem analysis. International Journal of Wilderness, 2006; 12(1):36-38.

18. Cohen J. The wildland-urban interface fire problem: A consequence of the fire exclusion paradigm. Forest History Today, 2008; Fall: 20-26.

19. González-Cabán A. Wildland fire management policy and fire management economic efficiency in the USDA Forest Service.
IV International Wildland Fire Conference Keynote Lecture. Seville, Spain, 2007.

20. Kahneman D, Tversky A. Prospect theory: An analysis of decision under risk. Econometrica, 1979; 47:263-291.

21. Camerer CF, Kunreuther H. Decision processes for low probability events: Policy implications. Journal of Policy Analysis and Management, 1989; 8(4):565-592.

22. Samuelson W, Zeckhauser R. Status quo bias in decisionmaking. Journal of Risk and Uncertainty, 1988; 1:7-59.

23. Gilovich T, Griffin D, and Kahneman D (eds). Intuitive Judgment: Heuristics and Biases. Cambridge, UK: Cambridge University Press, 2002.

24. Dawson NV, Arkes HR. Systematic errors in medical decision making. J Gen Intern Med, 1987; 2(3):183-187.

25. Bornstein BH, Emler AC. Rationality in medical decision making: A review of the literature on doctors' decision making biases. Journal of Evaluation in Clinical Practice, 2001; 7(2):97-107.

26. Wiseman D, Levin I. Comparing risky decision making under conditions of real and hypothetical consequences. Organ Behav Hum Dec, 1996; 66(3):241-250.

27. Ubell PA. Beyond costs and benefits: Understanding how patients make health care decisions. Oncologist, 2010; 15(1):510.

28. Peabody JW, Luck J, Glassman P, Dresselhaus TR, Lee M. Comparison of vignettes, standardized patients, and chart abstraction: A prospective validation study of 3 methods for measuring quality. Journal of the American Medical Association, 2000; 283(13):1715-1722.

29. McDaniels T, Axelrod LJ, Slovic P. Perceived ecological risk of global change: A psychometric comparison of causes and consequences. Global Environmental Change, 1996; 6(2):159171.

30. Slovic P. Perception of risk. Science, 1987; 236:280-285.

31. González-Cabán A. Managerial and institutional factors affect prescribed burning costs. For Sci, 1997; 43(4):535-543

32. Kahneman D, Klein G. Conditions for intuitive expertise: A failure to disagree. American Psychologist, 2009; 64(6):515526.

33. Reyna VF. How people make decisions that involve risk: A dual processes approach. Current Directions in Psychological Science, 2004; 13:60-66.

34. Shanteau J. Competence in experts: The role of task characteristics. Organ Behav Hum Dec, 1992; 53:252262.

35. US Department of Agriculture and US Department of Interior. Guidance for Implementation of Federal Wildland Fire Management Policy. National Interagency Fire Center, 2009.

36. McDaniel J. WFDSS: Taking decision support to the 21st century. Wildfire Lessons, 2007. Available at http://www.wildfirelessons.net/Additional.aspx?page $=96$. 